\title{
Modelos teóricos e interesses de mensuração no surgimento da pesquisa de inovação brasileira (Pintec)*
}

\author{
Diego Rafael de Moraes Silva** \\ André Tosi Furtado***
}

Recebido: 28/11/2015 Versão Revisada (entregue): 13/05/2016 Aprovado: 15/06/2016

\section{RESUMO}

O surgimento da Pesquisa de Inovação (Pintec), em 2002, constituiu uma novidade radical em termos de mensuração da inovação no Brasil. Porém, pouco se sabe sobre quais foram as motivações para sua realização. Nosso objetivo é analisar a gênese da Pintec. Para retraçar suas origens, realizamos entrevistas abertas com uma amostra intencional dos atores-chave envolvidos na sua construção conceitual-metodológica e fizemos uma revisão bibliográfica acerca da trajetória histórica dos indicadores de inovação e de seus modelos teóricos e interesses de mensuração. Partindo das entrevistas e da revisão bibliográfica, evidenciou-se que a Pintec é fruto de uma direta e incisiva demanda do Ministério da Ciência e Tecnologia (MCT), que a levou a adotar um modelo "híbrido" de survey de inovação, contemplando uma robusta seção acerca das atividades de $\mathrm{P} \& \mathrm{D}$, algo incomum nesse tipo de pesquisa. Concluímos que este modelo possui limitações, embora sejam inegáveis as contribuições da pesquisa para o debate sobre inovação no Brasil.

\footnotetext{
* Os autores gostariam de agradecer à Unicamp e ao CNPq pelo apoio financeiro e material oferecido e aos dois professores, presentes na banca de defesa da dissertação que originou o artigo, os quais avaliaram e forneceram importantes sugestôes de melhoria ao trabalho. Também somos gratos aos três pareceristas anônimos indicados pela $R B I$, que contribuíram muito para o aprimoramento do artigo. A responsabilidade por todo e qualquer equívoco, contudo, cabe unicamente aos autores.

** Universidade Estadual de Campinas (Unicamp), Campinas (SP), Brasil. E-mail: diegosilva@ige.unicamp.br

*** Universidade Estadual de Campinas (Unicamp), Campinas (SP), Brasil. E-mail: furtado@ige.unicamp.br
} 
PalaVras-CHaVe | Pintec; Pesquisas de Inovação; Indicadores de Inovação; Modelos de Mensuração

CÓdigos-JEL | O30

\section{Theoretical Models and Measurement Interests in the Rise of the Brazilian Innovation Survey (PINTEC)}

\section{ABSTRACT}

The rise of Brazilian Innovation Survey (PINTEC) in 2002 was a radical novelty in terms of innovation measurement in Brazil. However, little is known about the motivations for doing this survey. Our goal here is to analyze the genesis of PINTEC. To retrace its origins, we conducted unstructured interviews with a purposive sample of key-players involved in its conceptual-methodological design and did a literature review on historical trajectory of innovation indicators and their theoretical models and measurement interests. From the interviews and literature review we observed that PINTEC is the result of a direct and incisive demand by Ministry of Science and Technology, which led it to adopt a "hybrid" model of innovation survey covering a robust section on R\&D activities, something unusual in this type of survey. We concluded that this model has limitations, although the contributions of this survey to the debate on innovation in Brazil is undeniable.

KEYwORDS | PINTEC; Brazilian Innovation Survey; Innovation Surveys; Innovation Indicators; Measurement Models

JEL CODES | O30 


\section{Introdução}

No começo dos anos 2000 surgiu, juntamente com uma crescente ênfase política concedida ao conceito de inovação, a primeira pesquisa em nível nacional buscando produzir indicadores de inovação no Brasil, a Pesquisa Industrial-Inovação Tecnológica $2000^{1}$ (Pintec 2000), conduzida pelo Instituto Brasileiro de Geografia e Estatística (IBGE) e publicada em 2002 (ERBER, 2010). Embora a Pintec já esteja hoje na sua sexta edição, tendo fornecido ao longo dos últimos anos importantes indicadores para subsidiar análises sobre a inovação no país, pouco se sabe sobre as motivações originais para a realização desta pesquisa no Brasil e, em especial, quais foram os principais atores, modelos teóricos e interesses de mensuração por trás de tal consecução.

Evidentemente, existe uma ampla literatura especializada que fez uso da Pintec 2000 como instrumento de análise (KANNEBLEY; PORTO; PAZELLO, 2005; DE NEGRI; SALERNO, 2005; CAMPOS; IOOTTY, 2007) e, inclusive, alguns trabalhos que procuraram explorar, de uma perspectiva técnica, o processo de construção conceitual-metodológica da pesquisa (BASTOS; REBOUÇAS; BIVAR, 2003; IBGE, 2004). Todavia, tal literatura ainda é carente de estudos acerca do surgimento da Pintec que partam de uma perspectiva social, levando em conta os diversos atores envolvidos, seus respectivos interesses cognitivos e os arranjos institucionais necessários para que a pesquisa fosse criada. Acreditamos que este tipo de abordagem, já bastante corriqueiro na literatura internacional (GODIN, 2003; BARRÉ, 2004; GAULT, 2011), mereceria ser aplicado nacionalmente, complementando alguns trabalhos clássicos sobre indicadores de C\&T (VELHO, 1992, 2001) com estudos específicos sobre os determinantes sociais dos indicadores de inovação provenientes da Pintec.

Sustentamos no presente artigo, portanto, que um estudo acerca da origem desta pesquisa é relevante quando se considera que o contexto de produção das estatísticas define, em certa medida, suas fronteiras de utilização (SENRA, 2009; CAMARGO, 2009). Esta ideia proveniente da sociologia das estatísticas sublinha que escolhas conceituais e metodológicas são feitas na criação das pesquisas estatísticas, e levar em conta estas escolhas, bem como o contexto no qual foram feitas, é fundamental

1 Na edição 2003 a Pintec passou a se chamar "Pesquisa Industrial de Inovação Tecnológica". Já na edição 2005, em decorrência da adição de alguns serviços selecionados no universo de investigação, a Pintec passou a se chamar "Pesquisa de Inovação Tecnológica", nome que se manteve na edição 2008. Em 2011, sua denominação foi modificada para "Pesquisa de Inovação", tendo em vista que ela passou a contemplar as inovaçōes organizacionais e de marketing. 
para entender os limites e alcances das estatísticas (SENRA, 2009; CAMARGO, 2009). Isso significa que, sem compreender o contexto fundador dos indicadores de ciência, tecnologia e inovação (CT\&I), bem como de quaisquer outros, corre-se o risco de os utilizar inapropriadamente, cometendo, por exemplo, o que Freeman e Soete (2009) chamam de abuso dos indicadores de CT\&I.

A partir desta perspectiva, compreendemos que a Pintec, assim como qualquer outra pesquisa estatística, assume uma configuração conceitual-metodológica que é fruto das escolhas provenientes do seu contexto de surgimento. Tais escolhas, por conseguinte, delineiam os limites e alcances dos indicadores da Pintec, uma vez que eles, enquanto fundamentados em determinados modelos teóricos e interesses de mensuração acerca do fenômeno a ser medido, privilegiam certos aspectos da inovação em detrimento de outros. Logo, compreender tais escolhas é essencial para uma avaliação crítica desta pesquisa. ${ }^{2} \mathrm{O}$ objetivo geral do presente estudo é, portanto, identificar o papel dos diversos atores na gênese da Pintec. Para tanto, é retraçado todo o processo de construção conceitual-metodológica desta pesquisa, abordando os diferentes atores envolvidos, bem como seus distintos interesses de mensuração e modelos teóricos. A partir da compreensão acerca do modo que se chegou à configuração conceitual-metodológica adotada pela Pintec, esperamos ser possível apontar suas fragilidades, sem desconsiderar sua relevância e seu impacto para o variado público envolvido com a discussão de CT\&I no Brasil.

Conduzimos o estudo tomando por fundamento as metodologias de análises exploratórias, as quais, segundo Selltiz et al. ([1959] 1975), demandam um planejamento de pesquisa suficientemente flexível para permitir a consideração de muitos aspectos diferentes de um fenômeno. Com tal peculiaridade em mente, estes autores sugerem alguns métodos que são úteis nas pesquisas exploratórias: uma resenha da ciência social afim e de outras partes pertinentes da literatura; um levantamento de pessoas que tiveram experiência prática com o problema a ser estudado; e uma análise de exemplos que "estimulem a compreensão".

Em nossa investigação procuramos cobrir todos estes métodos sugeridos. Assim, foram feitas revisões bibliográficas e análises documentais, com evidente destaque para a análise das publicaçóes (manual de instruçôes, notas técnicas, questionário) da Pintec 2000, além da realização de entrevistas abertas com uma amostra intencional de sete atores-chave envolvidos na construção conceitual-metodológica da

2 Evidentemente, após a sua primeira edição a Pintec vivenciou importantes, porém incrementais, evoluçôes conceituais-metodológicas, as quais, todavia, não serão objeto de análise e avaliação no presente estudo. 
Pintec: Carlos Pacheco - secretário executivo do MCT (1999-2002); Evando Mirra - presidente do CNPq (1999-2001); Mariana Rebouças - pesquisadora do IBGE, que participou do planejamento da Pintec 2000; Sandra Hollanda - coordenadora da Assessoria de Acompanhamento e Avaliação do MCT (2000-2003); Sinésio Ferreira - chefe da Coordenação dos Indicadores de Ciência e Tecnologia do MCT (2000-2003); Virene Matesco - consultora do Banco Mundial junto ao MCT em projeto de indicadores de C\&T (1996-1998); e Wasmália Bivar - ex-presidente do IBGE, que coordenou a Pintec 2000. ${ }^{3}$ Selltiz et al. ([1959] 1975) frisam que, em se tratando de pesquisas exploratórias, é necessário que os atores de um estudo de experiência sejam cuidadosamente selecionados tendo em vista a capacidade de oferecerem as contribuições procuradas, o que justifica a utilização de um desenho amostral não probabilístico. Optamos por trabalhar com um questionário aberto também visando à flexibilidade metodológica demandada pelos estudos exploratórios. Utilizamos, especificamente, um roteiro de perguntas no sentido de conduzir a entrevista de acordo com algumas questóes-chave, as quais, a partir das respostas dos entrevistados, poderiam se desdobrar, e de fato se desdobraram, em outras questōes não antevistas pelo roteiro.

A seguir, comenta-se a relação entre modelos teóricos e mensuração da inovação e é traçado um breve retrato do que foram os esforços pioneiros de produção de indicadores de inovação no Brasil, procurando delinear o contexto no qual a Pintec surge, para compreender as escolhas e decisões por trás da construção da pesquisa. Posteriormente, é dado um enfoque especial a uma minuciosa análise acerca do surgimento da Pintec, apontando os limites e alcances da configuração conceitual-metodológica adotada pela pesquisa. Por fim, são tecidas algumas considerações finais a título de conclusão.

\section{Modelos teóricos e a mensuração da inovação}

As ideias de "modelos teóricos" e "interesses de mensuração" com as quais trabalhamos partem da constatação de que há modelos de concepção por trás de todos os indicadores, os quais seriam os "modelos teóricos" portados pelos atores que produzem as estatísticas, que direcionam a mensuração em tal ou qual maneira, evidenciando maiores "interesses de mensuração" por uns ou outros indicadores. Dessa forma, a construção dos indicadores de inovação, assim como a de qualquer

3 Para mais detalhes acerca das entrevistas, como as datas e locais onde foram realizadas, os roteiros de questōes e citaçōes diretas das mesmas, ver Silva (2015). 
outro, é precedida pela realização de determinadas escolhas relacionadas à relevância e ao papel das variáveis, o que reflete algum modelo de compreensão da natureza dos processos de inovação (VIOTTI, 2003). Portanto, cada uma das etapas de construção conceitual-metodológica de determinado indicador se apoia, implícita ou explicitamente, sobre um modelo de concepção da realidade a ser mensurada (BARRÉ; PAPON, 1993).

É possível apontar três modelos de compreensão da inovação que historicamente têm fundamentado a construção conceitual-metodológica de seus indicadores (VIOTTI, 2003). O pioneiro teria sido o modelo linear de inovação, segundo o qual existiria uma relação direta entre as quantidades e qualidades dos insumos utilizados em pesquisa, especialmente em pesquisa básica, e os resultados destes em termos de inovação tecnológica e, de maneira geral, de desenvolvimento econômico e social (STOKES, [1997] 2005). A visão da ciência básica e de sua forte relação com a inovação tecnológica se tornou o alicerce da política de C\&T norte-americana para as décadas após a Segunda Guerra Mundial, alcançando em seguida influência em nível global.

Posteriormente, todavia, diversos estudiosos do fenômeno da inovação começaram a indicar que as relações entre a tecnologia e a ciência são mais interativas e dialéticas do que o mero determinismo científico do modelo linear de inovação implicaria. Assim, o paradigma de política científica e tecnológica do pós-guerra, que consistia na visão estruturada do modelo linear sobre o papel da ciência básica na inovação tecnológica, passou a ser fortemente questionado nas décadas finais do século XX, sendo submetido a intensas pressōes e rigorosas revisões (STOKES, [1997] 2005).

Diante de diversas críticas ao modelo linear, especialmente de autores provenientes da economia evolucionária e neoschumpeteriana, elaborou-se um novo modelo de compreensão do processo inovativo, intitulado modelo elo de cadeia (chain-linked model) (VIOTTI, 2003). Na década de 1980, os pais de tal modelo, Kline e Rosenberg (1986), publicaram seu estudo seminal, destacando uma deficiência central no modelo linear: não existem vias de realimentação (feedback) no processo linear, isto é, não há trocas de informação e de pareceres entre os atores do processo. Para Kline e Rosenberg (1986), estas formas de realimentação são essenciais para avaliar o desempenho, formular os próximos passos e estimar a posição competitiva dos atores, sendo tais atividades inerentes ao processo de inovação, que é interativo e não necessariamente fundamentado em pesquisa básica. 
Nos anos 1990 foi formulado outro modelo alternativo ao linear, embasado na abordagem dos sistemas nacionais de inovação, apontando que a compreensão dos processos de produção, difusão e uso de inovaçôes deve abarcar a influência simultânea de fatores organizacionais, institucionais e econômicos, sendo tal modelo conhecido como modelo sistêmico (VIOTTI, 2003). Este modelo chama atenção para o fato de que as empresas não inovam de maneira isolada, mas sim num contexto de redes de relações diretas ou indiretas com outras empresas, com a infraestrutura de pesquisa pública e privada, com as instituições de ensino e pesquisa, com a economia nacional, com o sistema normativo e com um conjunto de outras instituições (NELSON, 1993; VIOTTI, 2003).

No geral, o modelo sistêmico não mostra discordâncias com o modelo elo de cadeia, representando uma expansão das variáveis a serem consideradas. Assim, do mesmo modo que o modelo elo de cadeia incorpora o modelo linear numa lógica mais complexa do processo de inovação, o modelo sistêmico incorpora o modelo elo de cadeia com a finalidade de abarcar a complexidade do fenômeno da inovação, tal como sintetizado no Quadro 1.

QUADRO 1

Síntese das principais características dos modelos de inovação

\begin{tabular}{|l|l|l|l|}
\hline & \multicolumn{1}{|c|}{ Modelo linear } & \multicolumn{1}{c|}{ Modelo elo de cadeia } & \multicolumn{1}{c|}{ Modelo sistêmico } \\
\hline Agente principal & $\begin{array}{l}\text { Instituições de pesquisa } \\
\text { ou laboratórios }\end{array}$ & Empresas & $\begin{array}{l}\text { Empresas em interação } \\
\text { com instituiçóes do sistema } \\
\text { de inovação }\end{array}$ \\
\hline $\begin{array}{l}\text { Natureza do } \\
\text { processo de } \\
\text { inovação }\end{array}$ & $\begin{array}{l}\text { Inovação como um } \\
\text { fenômeno ocasional }\end{array}$ & $\begin{array}{l}\text { Inovação como um processo } \\
\text { contínuo e interativo }\end{array}$ & $\begin{array}{l}\text { Inovaçáo como um processo } \\
\text { social e sistêmico }\end{array}$ \\
\hline $\begin{array}{l}\text { Posição da } \\
\text { pesquisa }\end{array}$ & Pesquisa precedendo a inovação & $\begin{array}{l}\text { Pesquisa como uma forma de } \\
\text { resolver problemas surgidos } \\
\text { em qualquer etapa do } \\
\text { desenvolvimento da inovação }\end{array}$ & $\begin{array}{l}\text { Pesquisa como uma atividade } \\
\text { num conjunto maior de } \\
\text { determinantes da inovação }\end{array}$ \\
\hline
\end{tabular}

Fonte: Adaptado de Viotti (2003).

Originalmente, a mensuração da inovação se baseou no modelo linear, que vigorou durante bastante tempo como uma das principais estruturas conceituais desenvolvidas para compreender a CT\&I e sua relação com a economia e a sociedade (GODIN, 2002). É verdade que esta estrutura conseguiu, em certa medida, identificar algumas das principais dimensões das atividades inovativas. Contudo, a produção estatística fundamentada em tal modelo não foi capaz de mensurá-las de maneira adequada, uma vez que da perspectiva linear bastaria empreender a mensuração dos inputs para conhecer os outputs, pois, nesse modelo, os insumos são garantias certas dos resultados. 
Baseada em tal entendimento, a mensuração da inovação começou a ser sistematicamente realizada em meados da década de 1960 por meio dos surveys de P\&D (GODIN, 2002). Sob a égide do modelo linear, os indicadores de P\&D eram concebidos como uma proxy legítima para se mensurar a inovação, uma vez que se pressupunha em tal modelo que a parte mais significativa das novas tecnologias era gerada dentro dos laboratórios de $\mathrm{P} \& \mathrm{D}$ e posteriormente aplicada à produção (ARCHIBUGI; SIRILLI, 2000; GODIN, 2002). Este modelo de mensuração fez com que fossem privilegiados os dados de $\mathrm{P} \& \mathrm{D}$ de tal modo que a Organização para a Cooperação e Desenvolvimento Econômico (OCDE), principal autoridade na mensuração de CT\&I desde então, desenvolveu na década de 1960 o Manual de Frascati, seu primeiro manual de coleta de estatísticas para a compreensão da dinâmica da inovação, o qual é destinado à captação das estatísticas de dispêndio e de pessoal ocupado em atividades de P\&D.

Ao longo da década de 1960, portanto, as iniciativas de mensuração da inovação se restringiam quase que exclusivamente à produção de indicadores de P\&D (GODIN, 2002). Isso, por um lado, devia-se à disseminada crença de que tais informações eram o bastante para entender a dinâmica da inovação e subsidiar políticas públicas neste âmbito, fazendo com que a preocupação com a mensuração dos outputs do processo fosse considerada de segunda ordem, e, por outro, também era devido ao contexto ainda carente de informaçôes sistematizadas para construção de indicadores referentes aos outputs. Todavia, logo nas décadas de 1970 e 1980, os estudiosos da inovação passaram a questionar fortemente o reducionismo na abordagem da inovação pelo modelo linear, demandando outras mensurações além de P\&D para se compreender a inovação (GODIN, 2002; FREEMAN; SOETE, 2009).

Num primeiro momento, tais críticas fomentaram a utilização dos dados de patentes enquanto indicadores de output do processo de inovação, de modo a se superar o viés de imput do modelo linear (ARCHIBUGI; SIRILLI, 2000). Contudo, é interessante notar que os dados de patentes, embora se refiram a resultados e não a insumos, também não estão totalmente dissociados do modelo linear de inovação, uma vez que constituem uma fonte de informaçôes sobre invençỗes, e não sobre inovações. Tendo em vista que as invenções usualmente possuem uma grande carga de pesquisa científica por trás de si, vemos que os dados de patentes enquanto proxy da inovação ainda indicam uma linearidade no modelo de compreensão deste fenômeno.

Num segundo momento, porém, tais críticas tornaram possível a abertura de uma janela de oportunidades para o desenvolvimento de métricas que poderiam 
abarcar satisfatoriamente a complexidade da inovação. O primeiro esforço sistemático internacional para mensurar diretamente a inovação teve início em 1988, na Escandinávia, com a ideia de construir um survey que possibilitasse comparações internacionais entre Noruega, Dinamarca, Finlândia e Suécia (HANSEN, 2001). Pesquisadores da OCDE foram convidados para participar de um workshop na Noruega com a finalidade de discutir tais indicadores. Foi então que a OCDE decidiu adotar o manual nórdico como seu próprio. Sua versão inicial foi discutida e aperfeiçoada em 1990 e 1991, sendo finalizada e adotada pela OCDE em 1992 com o título Proposed guidelines for collecting and interpreting innovation data, ficando conhecido como Manual de Oslo (GODIN, 2002).

Os novos indicadores de inovação produzidos pela metodologia do Manual de Oslo tomavam por base o modelo elo de cadeia para a compreensão da inovação, descartando a linearidade e o determinismo do então hegemônico modelo linear (HANSEN, 2001). Assim, uma figura central na fundamentação conceitual destes novos indicadores foi Nathan Rosenberg, um dos pais do modelo elo de cadeia, cujo trabalho afetou explicitamente a elaboração do Manual de Oslo (SMITH, 2004).

De acordo com Smith (2004), o trabalho de Rosenberg, e especialmente o seu trabalho em conjunto com Stephen Kline, trouxe pelo menos duas relevantes compreensões para o desenvolvimento dos novos indicadores de inovação: a novidade da inovação não envolve somente a criação de produtos ou processos completamente novos, mas também mudanças de pequena escala que podem, no longo prazo, ter grandes implicações tecnológicas e econômicas; e os insumos do processo de inovação não relacionados com as atividades de $\mathrm{P} \& \mathrm{D}$, tais como atividades de projeto (design), desenvolvimentos de engenharia e experimentação, treinamento, exploração de novos mercados, etc., são de grande importância. Desse modo, o Manual de Oslo se propunha a incorporar os parâmetros do Manual de Frascati, sugerindo uma nova leitura para a relação entre pesquisa e inovação, sendo a pesquisa vista como uma atividade complexa que ocorre em conjunto com o processo inovativo, e não uma precondição para este (BASTOS; REBOUÇAS; BIVAR, 2003).

Durante a década de 1990, passou-se a se pensar também em alternativas de indicadores de inovação baseados no modelo sistêmico, que seriam caracterizados por visar à identificação das características de funcionamento e, especialmente, das deficiências (falhas sistêmicas) de cada sistema nacional de inovação. Os esforços contemporâneos de desenvolvimento e sistematização de indicadores em consonância com o modelo sistêmico estão focados na mensuração de fluxos de recursos humanos, informaçôes e conhecimentos, bem como no mapeamento institucional 
dos sistemas nacionais de inovação e no comportamento inovador de suas empresas (VIOTTI, 2003).

Boa parte dos indicadores fundamentados no modelo sistêmico ainda se encontra, todavia, num estágio relativamente incipiente, não tendo sido objeto do desenvolvimento de metodologias padronizadas suficientemente maduras e aceitas internacionalmente, em especial por envolverem complexas integrações com indicadores econômicos e sociais (VIOTTI, 2003). Porém, é importante destacar que a evolução do Manual de Oslo e dos questionários baseados nas suas diretrizes metodológicas tem apresentado uma crescente incorporação de noções como redes, colaboração, cooperação, aprendizado interativo e o papel das instituições e da infraestrutura de C\&T, noçôes estas bastante salientadas pelo modelo sistêmico (SMITH, 2004; SALAZAR; HOLBROOK, 2004). Para concluir esta seção, apresentamos no Quadro 2 uma síntese dos principais indicadores-chave dos modelos de mensuração da inovação.

QUADRO 2

Síntese dos principais indicadores de inovação, por modelo de mensuração

\begin{tabular}{|c|c|c|}
\hline \multicolumn{3}{|c|}{ Principais indicadores de inovação } \\
\hline Modelo linear & Modelo elo de cadeia & Modelo sistêmico \\
\hline $\begin{array}{l}\text { Atividades de P\&D } \\
\text { Dispêndio em P\&D } \\
\text { Pessoal ocupado em } \\
\text { P\&D } \\
\text { Estatísticas de patentes }\end{array}$ & $\begin{array}{l}\text { Indicadores do modelo linear } \\
\text { Produtos e processos } \\
\text { tecnologicamente novos ou } \\
\text { substancialmente aprimorados } \\
\text { Atividades inovativas não } \\
\text { relacionadas com P\&D } \\
\text { Fontes de financiamento das } \\
\text { atividades inovativas } \\
\text { Fontes de informação da inovação } \\
\text { Relações de cooperação para } \\
\text { inovação } \\
\text { Impactos das inovações } \\
\text { Problemas e obstáculos à inovação }\end{array}$ & $\begin{array}{l}\text { Indicadores do modelo linear } \\
\text { Indicadores do modelo elo de } \\
\text { cadeia } \\
\text { Balanço de pagamentos } \\
\text { tecnológicos } \\
\text { Recursos humanos em C\&T } \\
\text { Informações bibliométricas } \\
\text { Indicadores de TICs } \\
\text { Produtividade } \\
\text { Capital de risco } \\
\text { Fusões e aquisições } \\
\text { Matrizes de insumo-produto } \\
\text { Investimentos intangíveis }\end{array}$ \\
\hline
\end{tabular}

Fonte: Adaptado de Archibugi \& Sirilli (2000). 


\section{Indicadores de inovação no Brasil: esforços pioneiros}

No começo da década de 1990, Matesco (1994a, 1994b) produziu uma série de trabalhos que têm como fonte o Censo Econômico de 1985 do IBGE, o qual só foi publicado em 1991. O IBGE incluiu neste censo informações, no âmbito das empresas industriais, referentes a três tipos de indicadores de inovação: gastos com P\&D; gastos com patentes; e gastos com pagamentos por Contratos de Licenciamento de Transferência Tecnológica.

Apesar de os trabalhos de Matesco (1994a, 1994b) terem significado um grande avanço no conhecimento acerca da inovação no Brasil, ainda permaneciam algumas dificuldades não superadas, tais como, por um lado, a ausência de pesquisas sistematicamente dedicadas à inovação no país e, por outro, o forte alinhamento dos dados de inovação coletados pelo Censo Econômico de 1985 com o modelo linear de inovação, não permitindo análises mais sofisticadas. É notável que os indicadores de inovação presentes neste censo referem-se, na verdade, a uma mensuração de insumos ao esforço tecnológico, uma vez que os três indicadores mencionados abordam apenas a questão dos gastos. Desse modo, entender a inovação a partir de quantificações apoiadas em modelos conceituais sofisticados, tais como o modelo elo de cadeia ou o modelo sistêmico, ainda era algo impossível naquele momento.

Os primeiros esforços no Brasil em termos de levantamentos especialmente dedicados às informações acerca da $\mathrm{P} \& \mathrm{D}$ empresarial vieram da Associação Nacional de Pesquisa e Desenvolvimento das Empresas Inovadoras (Anpei), que desenvolveu, a partir de 1992, uma base de dados, restrita aos seus associados, com informaçóes acerca das atividades empresariais de P\&D seguindo a metodologia da National Science Foundation dos EUA (ERBER, 2010).

Como aponta Bernardes (2003), esta pesquisa da Anpei contou, desde o início, com o suporte do governo federal por meio do Programa de Apoio à Capacitação Tecnológica da Indústria (Pacti) e de agências como a Financiadora de Estudos e Projetos (Finep) e o Serviço Brasileiro de Apoio às Micro e Pequenas Empresas (Sebrae). Porém, também é importante salientar que em nenhum momento tal pesquisa se enquadrou nos padróes dos surveys de P\&D da OCDE fundamentados no Manual de Frascati, uma vez que se tratava de um painel restrito às empresas associadas à Anpei. Ademais, por se tratar de uma pesquisa tão somente dedicada à $\mathrm{P} \& \mathrm{D}$ empresarial, o levantamento da Anpei se mostrava ainda fundamentado no modelo linear de concepção do processo de inovação, centrado majoritariamente na coleta de indicadores de insumo do processo inovativo. 
Coube ao Estado de São Paulo exercer o papel de liderança na produção de indicadores de inovação de empresas. Com o objetivo de mensurar o real dimensionamento dos impactos derivados das transformaçóes macroeconômicas sobre a estrutura produtiva paulista, a Fundação Sistema Estadual de Análise de Dados (Seade) passou a se dedicar, em meados dos anos 1990, à arquitetura de uma nova metodologia para captar os recentes processos econômicos e inovativos no estado (BERNARDES, 2003). Este objetivo motivou a elaboração da Pesquisa da Atividade Econômica Paulista (Paep), publicada em 1997, que continha uma seção dedicada à inovação que seguia a metodologia do Manual de Oslo da OCDE (ERBER, 2010).

De acordo com Bernardes (2003), a Paep foi uma iniciativa pioneira no cenário de produção estatística nacional, pesquisando um universo representativo de mais de 40.000 empresas industriais paulistas e incluindo no questionário um capítulo composto por nove questôes dedicadas às atividades inovadoras e rotinas de P\&D destas empresas. A metodologia utilizada para o survey de inovação na Paep foi a mesma recomendada pelo Manual de Oslo da OCDE e inspirada pelo questionário do primeiro Community Innovation Survey (CIS-1) do Gabinete de Estatísticas da União Europeia (Eurostat), de modo a garantir a comparabilidade dos indicadores (BERNARDES, 2003).

Em termos gerais, os indicadores de inovação tecnológica da Paep foram construídos a partir de cinco perspectivas: esforço de inovação; difusão de novas tecnologias; uso da tecnologia; origem e fontes das novas tecnologias; e impactos da tecnologia (BERNARDES, 2003). É notável, portanto, que a Paep demonstra um alinhamento bem maior com as pesquisas de inovação fundamentadas nos modelos elo de cadeia e sistêmico, diferentemente do que ocorria com a base de dados da Anpei e as variáveis de inovação cobertas pelo Censo Econômico de 1985 do IBGE, que compreendiam apenas indicadores de insumo atrelados à visão linear do processo de inovação.

Cumpre também mencionar o pioneirismo da Fundação de Amparo à Pesquisa do Estado de São Paulo (Fapesp) na iniciativa de organizar e disseminar, ainda no final dos anos 1990, os indicadores à disposição na publicação Indicadores de Ciência, Tecnologia e Inovação em São Paulo. Esta publicação da Fapesp, ainda que não se referisse a um esforço de mensuração em si, representou um importante trabalho de análise e organização sistemática dos indicadores de CT\&I da Paep e da Anpei, por exemplo, com vistas a avançar no entendimento acerca do processo inovativo no Estado de São Paulo. 


\section{0 surgimento da Pintec}

Em 2002 o IBGE publicou a Pintec 2000, que constituiu uma novidade radical em termos de mensuração da inovação no Brasil (ERBER, 2010). De fato, já há na literatura alguns trabalhos tentando dar conta do surgimento desta pesquisa, como é o caso de Bastos et al. (2003) e de IBGE (2004). Porém, cabe notar que nenhum destes estudos explora a fundo os antecedentes da Pintec 2000, isto é, o contexto motivacional que propiciou o surgimento da pesquisa, e tampouco discute de maneira pormenorizada um dos aspectos idiossincráticos mais interessantes da Pintec 2000, que é o detalhamento acerca da P\&D, em termos de atividades e pessoal ocupado, presente na pesquisa, algo totalmente estranho aos questionários típicos de surveys de inovação fundamentados no Manual de Oslo. Com vistas a abordar estes e outros aspectos de relevo não cobertos pela literatura, nos debruçaremos nos próximos parágrafos sobre uma análise minuciosa da configuração da Pintec e das motivações que a conduziram.

Entre 1996 e 1997 tiveram início articulações do Ministério da Ciência e Tecnologia $(\mathrm{MCT})^{4}$ com o IBGE, para a realização de uma pesquisa de inovação no Brasil. Virene Matesco, então consultora do Banco Mundial junto ao MCT nos projetos de implementação de coleta de dados básicos para constituição de indicadores de C\&T, foi ao IBGE por volta desta época para propor uma nova avaliação nacional da inovação nas empresas, algo que fosse mais amplo do que os estudos de caso existentes no Brasil (SILVA, 2015). Isso ocorreu logo no período de elaboração e divulgação da Paep por parte da Fundação Seade, o que também pode ter, em alguma medida, estimulado naquele momento a demanda do MCT pela produção de indicadores de inovação em nível nacional, como comentado por um dos nossos entrevistados:

Uma equipe do MCT vem ao IBGE lá naquele início, antes de 1998. Pode ser 1996 isso. Eles, então, falam da importância de começar a avaliar a inovação nas empresas brasileiras. Não havia registro, não havia informação. Já nos anos 1990, era uma preocupação vinda do MCT, para conhecer o que as empresas estavam realizando, de uma forma mais ampla que os estudos de caso. Nesta época surge a Paep. E é exatamente neste periodo em que a equipe do Seade pensa e elabora a

4 Em 2011, o Ministério teve o seu nome alterado para Ministério da Ciência, Tecnologia e Inovação (MCTI). Em 2016, o MCTI se fundiu com o Ministério das Comunicaçôes, dando origem ao Ministério da Ciência, Tecnologia, Inovaçôes e Comunicaçôes (MCTIC). 
Paep, que o MCT nos busca querendo uma visão mais ampla para a totalidade do País e não apenas para São Paulo.

Aqui cabe destacar que o terceiro Programa de Apoio ao Desenvolvimento Científico e Tecnológico (PADCT-III), que era o âmbito da consultoria prestada por Matesco ao MCT, dedicava toda uma seção de discussão sobre o suporte para monitoramento e avaliação setorial, bem como serviços de informação, cuja finalidade era melhorar a qualidade, cobertura e acesso de dados referentes ao desempenho do setor de C\&T, incluindo a produção de indicadores (BRASIL, 1998). É notável que no âmbito do PADCT-III os indicadores de P\&D eram vistos com grande estima. Colocava-se que as estatísticas de dispêndio nacional em P\&D teriam a meta de produzir um conjunto de informações quantitativas que traçassem o padrão nacional de investimento em $\mathrm{P} \& \mathrm{D}$, uma vez que havia o objetivo de incentivar esse investimento, fazendo com que a quantificação dessa informação fosse bastante relevante (BRASIL, 1998).

Tais elementos evidenciam a grande importância que o MCT concedia à tarefa de obter indicadores de P\&D desde meados dos anos 1990. A proposta que Matesco levou até o IBGE, contudo, foi um pouco distinta da ideia de realização de uma pesquisa inteiramente nova dedicada à $\mathrm{P} \& \mathrm{D}$ e inovação. Propunha-se, num primeiro momento, a criação de uma seção de inovação dentro da Pesquisa Industrial Anual (PIA), aos moldes, por exemplo, do que era o Censo Econômico de 1985, o qual coletava informações relacionadas à inovação dentro de um extenso levantamento econômico. Chegou-se, inclusive, a colocar uma questão dicotômica sobre a realização de dispêndios com capacitação tecnológica na PIA 1998, até para se utilizar posteriormente as respostas a essa pergunta para fazer marcações no cadastro das empresas com vistas à seleção de amostras (SILVA, 2015).

Incluir uma pesquisa de inovação dentro da PIA era, porém, praticamente impossível. Com efeito, esse tipo de pesquisa, tendo em vista a complexidade do tema abordado, demandaria um desenho metodológico próprio, sendo especificamente destinada a ser respondida por informantes qualificados e habituados com a temática da inovação, de modo a evitar os diversos problemas de viés que podem decorrer de um levantamento inadequado (ROMEIRO et al., 2014). Devido a esta incompatibilidade metodológica em termos da inclusão de perguntas sobre inovação numa pesquisa industrial abrangente, tal ideia foi abandonada, como comentado por um dos nossos entrevistados: 
A primeira demanda ao IBGE de uma pesquisa sobre inovação vem por meio do MCT na época em que a Virene estava lá. Mas era com uma ideia que depois, obviamente, foi de certo modo abandonada, que é assim: utilizando a própria Pesquisa Anual de Indistria [PIA] se poderia fazer dentro dela uma pesquisa de inovação [...] Mas depois a gente percebeu uma coisa relativamente grave nessa metodologia que era a seguinte: hoje e sempre a pesquisa de induistria [PIA] é uma pesquisa que levanta dados contábeis ou na área de recursos humanos; são as duas grandes áreas onde ela pega a totalidade das informaçôes. Assim, quem acabava respondendo àquela pergunta sobre se existiam atividades voltadas para a inovação não era alguém qualificado para responder. Então tinham falsos positivos, falsos negativos.

No final dos anos 1990 surgiu uma nova proposição do MCT, que incumbia ao próprio Ministério a responsabilidade de organizar a engenharia financeira para viabilizar a pesquisa (SILVA, 2015). Para entender essa proposição é necessário, contudo, compreender previamente as mudanças institucionais no âmbito do MCT naquele período. Primeiramente, é preciso entender que a situação precedente a tais mudanças não era das mais confortáveis. É verdade que nesse período a pós-graduação do país foi consolidada em decorrência de um considerável esforço de qualificação de pessoal e fortalecimento da pesquisa acadêmica, o qual deveria, em tese, ter sido acompanhado pelo fortalecimento tecnológico das empresas (PACHECO, 2007). Todavia, o êxito da pós-graduação, paralelamente ao pior desempenho do setor privado na época, reforçou a dimensão "ofertista" da política e a assimetria do sistema de C\&T brasileiro, que passou a ser caracterizado pelo confronto entre relativamente bons indicadores acadêmicos e piores números quanto às atividades de C\&T do setor privado (PACHECO, 2007).

Diante de tais fragilidades do lado empresarial da política de C\&T brasileira, no final dos anos 1990, durante o segundo governo FHC, passou a haver uma inédita ênfase concedida pelo Estado brasileiro às políticas de incentivo à inovação, configurando uma reforma da política nacional de C\&T com vistas a superar a histórica desarticulação entre essa política e a política industrial, bem como a mobilizar novos recursos para cessar a instabilidade histórica do gasto em C\&T (PACHECO, 2007). A convergência de opinióes em torno dessa mudança de agenda da política de C\&T se alimentou do enfoque compreensivo que foi concedido à política e suas metas, que surgia do amplo reconhecimento das transformações em curso da 
economia e do papel-chave que cumpria a C\&T e, especialmente, a inovação na construção das sociedades modernas (PACHECO, 2005). Dessa forma, a temática da inovação entrou na agenda da política nacional de C\&T neste período, ao passo que as empresas foram reconhecidas enquanto relevantes atores do sistema nacional de C\&T.

Para que tal mudança de agenda fosse realizada, foi necessária uma profunda reestruturação do próprio MCT, envolvendo a criação da Assessoria de Financiamento e Captação de Recursos, no âmbito da qual foram criados os Fundos Setoriais, e da Assessoria de Acompanhamento e Avaliação, no âmbito da qual se organizou uma Coordenação de Estatísticas e Indicadores de C\&T com o objetivo de consolidar a posição do Ministério como um abalizado formulador de políticas públicas e em que tiveram início as primeiras discussões que germinariam a proposição da Pintec (SILVA, 2015). Após alguns primeiros debates internos, a decisão do MCT foi a de ir ao IBGE demandando a realização de uma pesquisa nacional de inovação, uma vez que o instituto já tinha expertise com as pesquisas industriais, que possuíam uma configuração parecida com aquela necessária para levantar dados de CT\&I no setor privado. Além disso, havia também o fato de que o IBGE, com toda a sua credibilidade histórica, era a instituição adequada para garantir a qualidade e a legitimidade dos indicadores de inovação que seriam produzidos, algo bastante caro para o MCT na época (SILVA, 2015).

A discussão com o IBGE para realizar uma pesquisa de inovação em nível nacional começou ainda em 1999, mas se acelerou em 2000, sobretudo com a ideia da retomada das Conferências Nacionais de C\&T (SILVA, 2015). O documento Ciência, Tecnologia e Inovação: desafios para a sociedade brasileira, mais conhecido como Livro Verde, publicado em 2001 pelo MCT com o objetivo de subsidiar os debates da Conferência Nacional de Ciência, Tecnologia e Inovação (CT\&I), trazia alguns elementos interessantes acerca do debate sobre indicadores de inovação no Brasil. No Livro Verde é destacado que o Brasil vinha, há mais de duas décadas, contabilizando satisfatoriamente apenas os gastos em C\&T realizados pelo setor público, o que se justificaria pelo fato de que, historicamente, grande parte do esforço nacional em C\&T havia se concentrado nesse setor. Assim, não por acaso, a mensuração dos gastos privados em C\&T era ainda limitada, tendo em vista a inexistência de uma pesquisa abrangente e regular sobre o tema (BRASIL, 2001).

O Livro Verde ainda enfatiza que o Brasil se ressentia há anos da inexistência de elaboraçôes sistemáticas, contínuas e persistentes de informações e indicadores 
de CT\&I, enquanto, paralelamente, sublinha que, em nível federal, o MCT já havia dado início a uma ampla revisão na elaboração de indicadores (BRASIL, 2001). Nesta publicação há, especialmente, a menção ao fato de que o MCT vinha patrocinando um esforço maior, empreendido pelo IBGE, na montagem de uma pesquisa de abrangência nacional sobre inovação tecnológica que deveria, a partir de 2002, prover o Brasil de indicadores mais abrangentes sobre as atividades inovativas e de P\&D nas empresas (BRASIL, 2001). Cabe aqui notar que, sintomaticamente, os indicadores de resultado, de impacto e de interação presentes nos surveys de inovação não são mencionados, evidenciando, assim, a maior preocupação e o maior interesse, por parte do MCT, dedicados aos indicadores de insumo, especialmente àqueles relacionados com a $\mathrm{P} \& \mathrm{D}$.

Em 2001 foi então firmado um convênio entre o IBGE e a Finep para viabilizar financeiramente a Pintec 2000. Naquele momento, o IBGE não tinha condições de sustentar uma pesquisa deste porte, fazendo com que o MCT elaborasse uma engenharia financeira, por meio da Finep e dos novos recursos advindos dos recém-criados Fundos Setoriais, para afiançar os trabalhos do IBGE, tal como destaca um dos nossos entrevistados:

Quando a gente criou os fundos a situação era trágica, mas a gente nunca teve uma montanha de dinheiro. No último ano de governo em 2002, quando a gente saiu, a gente executou 250 milhões de reais, não muito mais do que isso. Mas isso viabilizou a ideia [de criar a Pintec]. A gente usou recursos da Finep para contratar, e foi um belo gasto. Ela [Pintec] não só permitiu a gente conhecer melhor o que faz, como permitiu também uma produção cientifica em artigos e documentos sobre inovação no Brasil.

$\mathrm{Na}$ esteira do convênio entre Finep e IBGE, também foi criado um grupo de trabalho formado por representantes destas duas instituições e do MCT, com o objetivo de acompanhar o planejamento e a execução técnica do projeto (IBGE, 2002). Tal grupo era formado por atores-chave por trás da Pintec 2000, tais como Wasmália Bivar e Mariana Rebouças, do IBGE, Sandra Hollanda e Sinésio Ferreira, do MCT, Antônio Cândido Daguer, Renato da Matta e Lenildo Fernandes, da Finep, e dois consultores da academia, José Eduardo Cassiolato e Jorge Britto, ambos do IE-UFRJ. As discussões foram posteriormente levadas para especialistas da academia, do governo e do setor privado, de modo a legitimar a fundamentação 
conceitual-metodológica da pesquisa também por parte de outros interlocutores interessados no tema (SILVA, 2015).

A Pintec 2000 adotou, ao fim das discussões, a metodologia sugerida pela segunda edição do Manual de Oslo da OCDE e, especificamente, o modelo proposto pelo Eurostat na terceira versão do Community Innovation Survey (CIS-3) (BASTOS; REBOUÇAS; BIVAR, 2003). A escolha do Manual de Oslo como fundamento metodológico deveu-se ao fato de ele ser, por um lado, um referencial mais completo do que o Manual de Frascati para o estudo da inovação e, por outro, um referencial mais rigoroso do que o Manual de Bogotá, o qual havia sido desenvolvido pela Red Iberoamericana de Indicadores de Ciencia y Tecnología (RICYT) com o intuito de estabelecer diretrizes metodológicas adequadas à captação das especificidades da inovação nos países latino-americanos (BASTOS; REBOUÇAS; BIVAR, 2003).

A escolha da fundamentação metodológica não se deu, todavia, sem disputas. Logo na discussão do projeto da Pintec 2000 havia, por um lado, um grupo que defendia a visão do Manual de Bogotá, com uma definição mais flexível e ampla do conceito de inovação, e, por outro, um grupo que defendia a visão do Manual de Frascati, com uma definição mais restrita do conceito de inovação, estreitamente próxima das atividades de $\mathrm{P} \& \mathrm{D}$, tal como comentado por um dos nossos entrevistados:

Então, havia esses dois extremos. Um que o pessoal do MCT, que é muito voltado para a P\&D, eu diria, era um pouco o porta-voz [...] a Finep e os grupos da Finep também sempre foram direcionados à $P \& D$. Era a experiência do cotidiano do ministério, e de outras áreas do ministério que trabalham com P\&D. Então, a preocupação deles era também ter retratada a $P \& D$. A discussão deles era "por que não um questionário de P\&D que não havia no Brasil naquele momento?" [...] Havia outro grupo que defendia a visão do Manual de Bogotá, no qual tinha que haver também [inovações] organizacionais já naquela época na pergunta de inovação [...] ai vinha a força da academia e a força também de pessoas egressas da academia dentro do MCT e dentro da Finep dizendo "não, nós temos que ver algo mais amplo para o Brasil do que a P\&D apenas".

Assim, como se vê, podemos dizer que o segundo grupo era, em boa medida, constituído por acadêmicos ou egressos da academia no MCT e na Finep que mantinham proximidade com a RICYT e com as discussões sobre as particularidades da inovação em países periféricos, ao passo que o primeiro grupo era, em boa parte, proveniente da esfera de política pública, que representava a experiência do cotidia- 
no do MCT e da Finep, a qual era direcionada às discussóes acerca das atividades empresariais de P\&D (SILVA, 2015).

De fato, a demanda inicial do MCT era muito voltada para a necessidade de se mensurar a $P \& D$ empresarial no Brasil, de modo que é equivocado dizer que o levantamento de P\&D apenas tomou carona na Pintec, mas, sim, constituiu uma preocupação fundamental, já que naquele momento se julgava de grande importância conhecer com maior precisão qual era o gasto privado em P\&D no país (SILVA, 2015). Embora se soubesse que inovação é um conceito mais amplo do que $P \& D$, o fato de não se ter uma ideia consistente do que acontecia em termos de gastos privados em P\&D no Brasil foi a primeira motivação da Pintec, como comentado por um dos nossos entrevistados:

Inovação é um conceito mais amplo que $P \& D$, mas o fato de a gente não ter a menor ideia do que acontecia em termos de gastos privados em $P \& D$ foi a primeira motivação da Pintec. O essencial era a precariedade dos [dados sobre] gastos em $P \& D[. .$.$] a principal demanda era conseguir aferir o dispêndio em P \& D$. Isso era a coisa mais crítica, não tinha nada sobre isso na época. Depois isso evoluiu para a gente fazer uma pesquisa sobre inovação no sentido de captar outras dimensões da inovação: o esforço inovador, as razôes para inovar, a capacidade para inovar e etc. Então ela evoluiu de uma necessidade de dados de P\&D para uma coisa mais sofisticada.

Diante desta demanda tão incisiva do MCT por indicadores de P\&D e, paralelamente, da demanda de acadêmicos por conceitos abrangentes de inovação, foi necessário que a Pintec 2000 assumisse uma configuração que satisfizesse estas duas visões, abarcando tanto as mensurações de $\mathrm{P} \& \mathrm{D}$, que era a principal demanda do Ministério, quanto conceitos abrangentes de inovação, com adaptações do Manual de Oslo à realidade brasileira. Chegou-se, assim, a um consenso de que um modelo adaptado ou "híbrido" atenderia às necessidades de uma pesquisa de inovação no Brasil, adotando para a Pintec um modelo de survey de inovação que contemplava questôes aprofundadas sobre a $\mathrm{P} \& \mathrm{D}$, tal como comentado por um dos nossos entrevistados:

Veja, nós não tínhamos a [pesquisa] de $P \& D$, então foi mais fácil politicamente estar trazendo a argumentação de que no país a $P \& D$ não é tão grande, então tem que ser esse conceito mais amplo de inovação e não inovação entendendo ela 
apenas por $P \& D$. O argumento para aquelas pessoas que falavam "eu preciso $d a$ [mensuração de] $P \& D$ ” era “nós temos aqui dentro desse questionário". A nossa "jabuticaba" era colocar aquele capitulo do pessoal em P\&D no questionário, porque nós pegamos o questionário de $P \& D$ e trouxemos para dentro do questionário da pesquisa de inovação.

A avaliação do núcleo de especialistas envolvidos com o desenho da Pintec 2000 foi a de que, com algumas adaptações na sua aplicação e cuidado na interpretação dos resultados, seria possível realizar, com resultados satisfatórios mesmo em países periféricos, uma pesquisa de inovação nos marcos do Manual de Oslo (SILVA, 2015). Bastos et al. (2003) destacam que, em relação às atividades de P\&D, por exemplo, haveria que se flexibilizar seu critério de avaliação e mensuração, considerando as condições muitas vezes assistemáticas e informais dos arranjos encontrados em empresas brasileiras. Ainda assim, deveria se tomar um cuidado especial para que os critérios abrangentes adotados não comprometessem a comparabilidade internacional dos resultados. Segundo os autores, estes ajustes deveriam ser obtidos na própria operacionalização da pesquisa, o que envolveu, por exemplo, a formulação de um manual do entrevistado e um rigoroso treinamento dos entrevistadores.

A operacionalização da Pintec 2000 foi possivelmente um dos aspectos da pesquisa mais discutidos. Era essencial que uma pesquisa desta complexidade e inédita no país fosse operacionalizada com o maior cuidado possível. Tendo isso em vista, a equipe de pesquisadores do IBGE procurou se munir desde o início com uma minuciosa operacionalização, que inclusive se tornou um diferencial da Pintec em relação aos demais surveys de inovação em outros países, como comentado por um dos entrevistados:

A gente tinha absoluta consciência de que a forma de fazer a pesquisa era fundamental [...] e nesse sentido o cuidado do IBGE foi primoroso [...] Eu acho que têm cuidados metodológicos que inclusive superam a própria metodologia das pesquisas recomendadas pelo Eurostat, e eu acho que épelo fato de que a gente estava fazendo pela primeira vez, as empresas não tinham contabilidade de P\&D, e o conceito em si é um conceito difícil, é um conceito complexo.

De acordo com Bastos et al. (2003), a escolha das formas de captura das informações empregadas na Pintec 2000 levou em consideração os seguintes fatores:

- o termo “inovação" pode apresentar múltiplas significações inerentes à própria complexidade do conceito de inovação; 
- esta é a primeira pesquisa realizada pelo IBGE neste tema e, portanto, não há conhecimento prévio que possa orientar a identificação de problemas de entendimento das questóes propostas;

- em países como o Brasil as atividades de inovação tecnológica são, provavelmente, ocasionais e organizadas em estruturas informais e, portanto, espera-se que as empresas não estejam familiarizadas com os conceitos e definições utilizados.

O desenho amostral adotado pela Pintec 2000 também é digno de menção. O principal elemento que deve ser sublinhado refere-se ao escopo da pesquisa, que compreende apenas o setor industrial, e não o setor industrial e o setor de serviços, tal como recomendava a segunda edição do Manual de Oslo. Isso deveu-se ao fato de que a mensuração da inovação nos serviços é mais complexa do que na indústria, levando à decisão de restringir esta pesquisa, que estava sendo realizada num país sem tradição neste tipo de investigação, ao setor industrial (SILVA, 2015). Já em termos de conteúdo, a Pintec 2000 assumiu uma estrutura lógica similar àquela do CIS-3, sendo que a maior diferença é o extenso módulo dedicado à captação de informações sobre a P\&D.

Quando confrontamos os questionários do CIS-3 (EUROSTAT, 2001) e da Pintec 2000 (IBGE, 2002), tornam-se perceptíveis algumas importantes adaptações que a equipe envolvida no desenho da Pintec 2000 fez com relação às diretrizes metodológicas do Manual de Oslo e ao modelo do CIS-3. Dentre as especificidades de um questionário em relação ao outro, são notáveis, por um lado, algumas adaptaçōes na Pintec 2000 que sugerem concessóes ante a demanda do grupo entusiasta do Manual de Bogotá, tais como a identificação da origem do capital controlador da empresa e do pertencimento e posição da empresa num grupo empresarial, o que remete ao papel de destaque das multinacionais nos países periféricos. Por outro lado, também são notáveis algumas adaptaçôes na Pintec 2000 que sugerem concessōes em relação à demanda do grupo preocupado com a mensuração da $\mathrm{P} \& \mathrm{D}$, tais como os questionamentos acerca da localização das atividades de P\&D da empresa, da destinação de um percentual de faturamento para as atividades de P\&D e dos níveis de qualificação, postos de ocupação e graus de dedicação do pessoal ocupado em atividades de $\mathrm{P} \& \mathrm{D}$, além da distinção feita entre as atividades de $\mathrm{P} \& \mathrm{D}$ e as outras atividades inovativas para investigação das fontes de financiamento. Tais peculiaridades, dentre outras, podem ser observadas no Quadro 3. 


\section{Quadro 3}

Síntese das principais peculiaridades dos questionários da Pintec 2000 e do CIS-3

\begin{tabular}{|c|c|c|}
\hline Classe de indicadores & CIS-3 & Pintec 2000 \\
\hline $\begin{array}{l}\text { Características } \\
\text { econômicas da empresa }\end{array}$ & $\begin{array}{l}\text { Dedica maior esforço na coleta } \\
\text { de informaçôes econômicas } \\
\text { básicas da empresa, tais } \\
\text { como volume de negócios, } \\
\text { exportaçōes, investimento bruto } \\
\text { em bens tangíveis e número de } \\
\text { empregados }\end{array}$ & $\begin{array}{l}\text { Dedica maior esforço na } \\
\text { identificação da origem do capital } \\
\text { controlador da empresa e do } \\
\text { pertencimento e posição da empresa } \\
\text { num grupo empresarial }\end{array}$ \\
\hline Inovação de produto & $\begin{array}{l}\text { Procura coletar uma breve } \\
\text { descrição da inovação de produto } \\
\text { mais importante da empresa } \\
\text { e também uma estimativa da } \\
\text { distribuição do volume de } \\
\text { negócios entre os produtos } \\
\text { tecnologicamente novos ou } \\
\text { substancialmente aprimorados } \\
\text { e aqueles inalterados ou } \\
\text { marginalmente modificados }\end{array}$ & \\
\hline Inovação de processo & $\begin{array}{l}\text { Procura coletar uma breve } \\
\text { descrição da inovação de processo } \\
\text { mais importante da empresa }\end{array}$ & $\begin{array}{l}\text { Diferencia entre inovação de } \\
\text { processo nova para a empresa e } \\
\text { inovação de processo nova para o } \\
\text { setor de atuação da empresa }\end{array}$ \\
\hline $\begin{array}{l}\text { Projetos incompletos } \\
\text { ou abandonados }\end{array}$ & $\begin{array}{l}\text { Aborda em termos de atividades } \\
\text { inovativas e não de projetos, } \\
\text { destacando as atividades de P\&D }\end{array}$ & $\begin{array}{l}\text { Diferencia entre projetos de } \\
\text { produto ou de processo incompletos } \\
\text { ou abandonados no período de } \\
\text { referência }\end{array}$ \\
\hline Atividades inovativas & & $\begin{array}{l}\text { Procura coletar informaçóes } \\
\text { acerca do grau de importância das } \\
\text { atividades inovativas }\end{array}$ \\
\hline $\begin{array}{l}\text { Fontes de } \\
\text { financiamento das } \\
\text { atividades inovativas }\end{array}$ & $\begin{array}{l}\text { Aborda por meio de } \\
\text { questôes dicotômicas acerca } \\
\text { do financiamento público } \\
\text { diferenciando por níveis } \\
\text { geográficos }\end{array}$ & $\begin{array}{l}\text { Aborda por meio de questōes acer- } \\
\text { ca de percentuais do dispêndio } \\
\text { advindos de fontes próprias ou } \\
\text { de terceiros, privadas ou públicas, } \\
\text { para o financiamento de atividades } \\
\text { inovativas, diferenciando entre ativi- } \\
\text { dades de P\&D e outras atividades }\end{array}$ \\
\hline $\begin{array}{l}\text { Atividades internas de } \\
P \& D\end{array}$ & & $\begin{array}{l}\text { Questiona acerca da localização } \\
\text { de concentração das atividades de } \\
\mathrm{P} \& \mathrm{D} \text { da empresa, da destinação de } \\
\text { um percentual de faturamento para } \\
\text { as atividades de } \mathrm{P} \& \mathrm{D} \text { e dos níveis } \\
\text { de qualificação, postos de ocupação } \\
\text { e graus de dedicação do pessoal } \\
\text { ocupado em atividades de } \mathrm{P} \& \mathrm{D}\end{array}$ \\
\hline
\end{tabular}


Quadro 3

Síntese das principais peculiaridades dos questionários da Pintec 2000 e do CIS-3

\begin{tabular}{|c|c|c|}
\hline Classe de indicadores & CIS-3 & Pintec 2000 \\
\hline Impactos das inovaçôes & & $\begin{array}{l}\text { Questiona acerca da distribuição } \\
\text { percentual do valor das vendas } \\
\text { internas e das exportaçōes segundo } \\
\text { o grau de novidade dos produtos }\end{array}$ \\
\hline Fontes de informação & & $\begin{array}{l}\text { Aponta mais possíveis fontes } \\
\text { de informação para inovar, tais } \\
\text { como: departamento de P\&D } \\
\text { interno, empresas de consultoria } \\
\text { e consultores independentes, } \\
\text { centros de capacitação profissional } \\
\text { e assistência técnica, instituições } \\
\text { de testes, ensaios e certificações, } \\
\text { aquisição de licenças, patentes e } \\
\text { know-how, redes de informações } \\
\text { e também demanda a localização } \\
\text { da principal fonte de informação, } \\
\text { diferenciando entre Brasil e exterior }\end{array}$ \\
\hline $\begin{array}{l}\text { Relaçôes de cooperaçãoo } \\
\text { para inovação }\end{array}$ & $\begin{array}{l}\text { Aponta os laboratórios comerciais } \\
\text { ou empresas de } \mathrm{P} \& \mathrm{D} \text { como } \\
\text { possíveis parceiros para inovar }\end{array}$ & $\begin{array}{l}\text { Aponta os centros de capacitação } \\
\text { profissional e assistência técnica } \\
\text { como possíveis parceiros para inovar }\end{array}$ \\
\hline Suporte do governo & $\begin{array}{l}\text { Não possui essa classe de } \\
\text { indicadores }\end{array}$ & $\begin{array}{l}\text { Aborda por meio de questão } \\
\text { dicotômica sobre o recebimento } \\
\text { de suporte do governo para as } \\
\text { atividades inovativas } \\
\end{array}$ \\
\hline Patentes & $\begin{array}{l}\text { Além das patentes, também } \\
\text { questiona sobre outros métodos } \\
\text { de proteção, como métodos } \\
\text { formais e métodos estratégicos, e } \\
\text { demanda o número de patentes } \\
\text { solicitadas e em vigor }\end{array}$ & $\begin{array}{l}\text { Questiona sobre onde a empresa } \\
\text { solicitou o depósito de patente, } \\
\text { diferenciando entre Brasil e exterior }\end{array}$ \\
\hline $\begin{array}{l}\text { Problemas e obstáculos } \\
\text { à inovação }\end{array}$ & $\begin{array}{l}\text { Questiona o tipo de problema } \\
\text { que a atividade inovativa pode } \\
\text { ter enfrentado em vez de utilizar } \\
\text { uma questáo dicotômica }\end{array}$ & $\begin{array}{l}\text { Aponta mais possíveis fatores } \\
\text { prejudiciais às atividades inovativas, } \\
\text { tais como escassas possibilidades de } \\
\text { cooperação com outras empresas } \\
\text { ou instituiçôes e escassez de serviços } \\
\text { técnicos externos adequados }\end{array}$ \\
\hline $\begin{array}{l}\text { Outras importantes } \\
\text { mudanças estratégicas e } \\
\text { organizacionais }\end{array}$ & & $\begin{array}{l}\text { Aponta também como possível } \\
\text { mudança a implementação de novos } \\
\text { métodos e gerenciamento, visando } \\
\text { atender normas de certificação, } \\
\text { e questiona a importância da } \\
\text { inovação tecnológica como fator de } \\
\text { diferenciação competitiva da empresa }\end{array}$ \\
\hline
\end{tabular}

Fonte: Elaboração própria com base em IBGE (2002) e Eurostat (2001). 
Assim, embora a principal demanda de política pública fosse por indicadores de P\&D, é interessante notar que a Pintec surge já inserida na chamada "segunda geração" metodológica de pesquisas de inovação, isto é, alinhada com as metodologias fundamentadas no Manual de Oslo, que entendem a inovação tecnológica como um processo amplo e complexo, indo além daquilo que surge das atividades de P\&D (BASTOS; REBOUÇAS; BIVAR, 2003). Ou seja, tal como o CIS-3, a Pintec 2000 está conceitualmente fundamentada no modelo elo de cadeia e, portanto, procura superar as limitações do modelo linear na mensuração da inovação.

Desde a sua primeira edição, o Manual de Oslo é enfático em sua crítica ao modelo linear de inovação e aos indicadores que dele são derivados, especialmente àqueles de $\mathrm{P} \& \mathrm{D}$, os quais conduzem à concepção equívoca de que as atividades de pesquisa são invariavelmente o carro-chefe da inovação, fazendo com que muitas vezes as políticas de inovação sejam vistas tão somente como políticas de P\&D (OECD, 1992). Alternativamente, a proposta do Manual de Oslo é fornecer diretrizes à mensuração da inovação de uma perspectiva mais completa, contemplando dados acerca da estrutura da inovação nas empresas, o modo como elas adquirem capacidades inovativas, os principais obstáculos com os quais se deparam e, sobretudo, o papel das atividades inovativas não relacionadas à $P \& D$ no processo de inovação (OECD, 1992). Para dar conta desse entendimento mais sofisticado do processo de inovação, adotou-se o modelo elo de cadeia enquanto modelo conceitual de mensuração na proposta do Manual de Oslo, uma vez que tal modelo concebia a inovação de uma perspectiva mais interativa e complexa (OECD, 1992).

$\mathrm{O}$ modelo linear parte do pressuposto de que o elemento central para a inovação é a ciência, quando, na verdade, é o projeto, no entender de Kline e Rosenberg (1986). Para eles, o projeto é fundamental para dar início às inovaçôes, e processos de reprojeto são imprescindíveis para alcançar o sucesso, uma vez que com os fluxos de realimentação as inovações vão tomando, de maneira incremental, as formas adequadas para sua ampla difusão e comercialização. $\mathrm{O}$ ponto dos autores não é sugerir que a ciência é irrelevante, mas sim chamar a atenção para o fato de que a maioria das inovaçóes é feita pelas empresas com conhecimento prontamente elaborado e disponível, sendo necessária a realização de pesquisa científica apenas quando este conhecimento à disposição não é o bastante para resolver determinados problemas. No modelo elo de cadeia a empresa e a atividade empresarial desempenham, portanto, papel central, e não mais periférico, tal como ocorria no modelo linear. Nele a ênfase se dá sobre a concepção de que a inovação é resultado de um processo de interação entre oportunidades de mercado e a base de conhecimentos 
e capacitações das empresas, envolvendo inúmeros processos que não apresentam uma sequência claramente definida (KLINE; ROSENBERG, 1986).

Aderindo à conceituação e à metodologia de survey propostas pelo Manual de Oslo, a Pintec 2000 adotou uma estrutura de temas com a finalidade de suprir a produção em nível nacional de estatísticas empresariais sobre os seguintes tópicos: atividades inovativas; fontes de financiamento; atividades internas de P\&D; impactos das inovações; fontes de informação para inovar; relações de cooperação na inovação; suporte do governo; patentes; problemas e obstáculos à inovação; e mudanças estratégicas e organizacionais. Assim, embora no escopo da Pintec 2000 se encontrem também os tradicionais indicadores de inovação fundamentados no modelo linear, isto é, os indicadores de atividades internas de P\&D e de patentes, é notória a amplitude temática da pesquisa, a qual, embasada no modelo elo de cadeia, fornece novos indicadores de inovação que tentam dar conta do caráter interativo e incremental do processo inovativo.

Para explicar essa opção, além da já mencionada pressão advinda dos acadêmicos ligados aos estudos das especificidades da inovação em países periféricos, é necessário também recordar que, na época em que surgiu a Pintec, vários países estavam adotando ou já haviam adotado a metodologia do Manual de Oslo. Isso não apenas na Europa, mas em diversas partes do mundo, como na América Latina, na Oceania e na África. Portanto, adotar esta metodologia, que era considerada a fronteira em termos de pesquisa sobre inovação, era algo natural naquele momento. Porém, cabe realçar que, diferentemente da maioria dos casos internacionais, o Brasil nunca possuíra antes pesquisas sistemáticas de $\mathrm{P} \& \mathrm{D}$ empresarial fundamentadas no modelo linear. Mesmo os exemplos do Censo Econômico de 1985 e dos levantamentos da Anpei não se configuram como pesquisas deste tipo, dado o seu caráter esporádico e a ausência de rigor metodológico necessário às pesquisas de $\mathrm{P} \& \mathrm{D}$, usualmente fundamentadas pelo Manual de Frascati nos países da OCDE.

Nesses países, as pesquisas de inovação costumam ser feitas separadamente das de P\&D, mesmo porque elas requerem diferentes rotinas de amostragem. Mas, ainda assim, não se descarta que elas sejam executadas integradamente. Entretanto, cabe notar que os estudos da OCDE geralmente utilizam as informaçóes de P\&D advindas dos surveys de $\mathrm{P} \& \mathrm{D}$, o que sugere uma maior confiança por parte desta instituição nos dados deste tipo de pesquisa. De fato, existe uma controvérsia entre os estudiosos da mensuração da inovação acerca do modelo adequado para se mensurar a P\&D, questionando se seria por meio dos surveys de inovação ou dos surveys de P\&D. Francoz e Patinson (2000) ressaltam que estes dois tipos de 
pesquisa produziram, ao longo dos anos, diferentes estimativas das atividades e dos dispêndios em P\&D em diversos países da OCDE. Dentre os possíveis motivos que estariam por trás destas diferenças, destacam-se os seguintes:

- diferentes definiçôes de P\&D - enquanto os surveys de P\&D geralmente fornecem definições detalhadas e exemplos de quais atividades seriam consideradas atividades de P\&D, os surveys de inovação trabalham com definiçōes abrangentes, compreendendo inclusive a ideia de atividades ocasionais de P\&D;

- diferentes métodos de amostragem - enquanto usualmente os surveys de $\mathrm{P} \& \mathrm{D}$ são censos de empresas que executam P\&D, os surveys de inovação compreendem geralmente amostras aleatórias estratificadas de empresas no escopo da pesquisa;

- diferentes taxas de resposta - enquanto as taxas de resposta dos surveys de inovação são geralmente baixas, as dos surveys de P\&D são normalmente altas;

- diferentes períodos de referência - embora ambos os surveys procurem mensurar as atividades de P\&D num ano específico, os surveys de inovação normalmente coletam apenas informações a respeito das empresas que declararam ter inovado ou ter tido projetos de inovação abandonados ou incompletos no período de três anos precedente em relação ao ano de referência.

Destes motivos descritos, podemos assinalar que a Pintec 2000 supera as restriçôes apresentadas no terceiro motivo, uma vez que a taxa de resposta desta pesquisa é superior a 90\%, e considera o primeiro motivo algo não problemático, visto que se supunha que no Brasil uma grande parcela das atividades de P\&D seria informal e não contínua. Já o segundo e o quarto motivos, bastante atrelados ao fato de que os surveys de $\mathrm{P} \& \mathrm{D}$ são praticamente censos daquelas empresas que realizariam as atividades de $\mathrm{P} \& \mathrm{D}$, são fatores que provavelmente tornam limitados os indicadores de P\&D da Pintec 2000.

Além desta dificuldade em coletar de modo rigoroso as estatísticas de P\&D, há ainda algumas dificuldades interpretativas dos surveys de inovação em geral no que toca as estatísticas não relacionadas com $\mathrm{P} \& \mathrm{D}$, as quais, a princípio, deveriam ser o elemento de destaque destas pesquisas. Tais dificuldades interpretativas representam uma das principais razões por trás da subutilização dos indicadores de inovação destes surveys na formulação, acompanhamento e avaliação de políticas públicas em diversos países da Europa, Oceania e América Latina, tal como destacado pelos trabalhos de Arundel (2007) e Baptista et al. (2010). 
Segundo estes autores, os indicadores de inovação em maior sintonia com os modelos elo de cadeia e sistêmico sofreriam de uma subutilização no âmbito de política pública por serem pouco amigáveis à racionalidade da política, o que faria com que ainda prevalecessem neste âmbito os indicadores de inovação alinhados com o modelo linear, especialmente os indicadores de $\mathrm{P} \& \mathrm{D}$, que possuem maior sintonia com os tradicionais instrumentos de políticas de inovação (ARUNDEL, 2007; BAPTISTA et al., 2010). Esta é, portanto, uma vulnerabilidade da totalidade dos surveys de inovação fundamentados na metodologia do Manual de Oslo da OCDE, não de pesquisas em particular, como a Pintec.

É também preciso sublinhar que na Europa os surveys de P\&D, em comparação com os de inovação, possuem maior legitimidade política. Esterle e Theves (2005) destacam que, com relação às estatísticas de P\&D, os governos têm uma relativa dependência da coleta destes dados, centralizando sua produção, enquanto a produção de estatísticas alinhadas com o Manual de Oslo é mais descentralizada, sendo relegada na maioria dos casos a instituiçôes outras que os escritórios nacionais de estatística. Esta característica nos leva a crer que, se em algum momento houver a necessidade, por questōes orçamentárias ou afins, de interromper a série de algum destes surveys, é provável que na Europa seja interrompido o survey de inovação.

No caso da Pintec, esta adoção de um modelo de integração dos dois tipos de survey certamente contribui para que seja mais difícil a interrupção da pesquisa, haja vista que ela é a única fonte de informaçōes empresariais sobre inovação no Brasil. Tal modelo, portanto, confere certa "proteção"à Pintec, algo que carece aos seus congêneres europeus. Também é digno de menção o fato de que, por ser conduzida pelo órgão estatístico oficial do Brasil, a Pintec permite que haja uma diversa e proveitosa integração com as demais estatísticas produzidas pelo IBGE, especialmente com as estatísticas da PIA, as quais, além de permitirem uma qualificação dos próprios dados quantitativos da Pintec, fornecem indicadores interessantes para confronto entre atividades inovativas e desempenho de mercado (BASTOS; REBOUÇAS; BIVAR, 2003).

\section{Considerações finais}

Neste artigo procuramos esclarecer como se deu a construção conceitual-metodológica da Pintec e qual foi o papel dos diversos atores, bem como de seus modelos teóricos e interesses de mensuração, em tal processo. A relevância da análise aqui empreendida 
deve-se à percepção de que o contexto de produção das estatísticas define, em certa medida, suas fronteiras de utilização. Isto é, as escolhas conceituais-metodológicas feitas na criação das pesquisas estatísticas são definidoras das possibilidades e impossibilidades de utilização apropriada das estatísticas. Sem compreender, portanto, este contexto de origem e suas escolhas, corre-se o risco de fazer uso inapropriado das estatísticas, seja elas de CT\&I ou quaisquer outras.

Constatamos que o grande interesse de mensuração do MCT, um dos principais atores nesse processo, se centrava na $\mathrm{P} \& \mathrm{D}$ empresarial, algo, de fato, pouco explorado pelas estatísticas disponíveis até então. A maior proximidade dos instrumentos tradicionais de política de inovação com o modelo linear gerava esse maior interesse por estatísticas de P\&D. Portanto, o modelo teórico linear, portado pela experiência de cotidiano dos atores de políticas públicas, foi fundamental na configuração desta demanda, direcionando fortemente os interesses de mensuração à questão da $\mathrm{P} \& \mathrm{D}$ empresarial.

A demanda inicial do MCT, todavia, evoluiu no sentido de se fazer um survey de inovação baseado no Manual de Oslo da OCDE. Mas, para isso, foi essencial o papel desempenhado por outros atores também interessados na mensuração da inovação no Brasil. Na verdade, observamos que havia inclusive uma demanda por parte de acadêmicos ligados às discussões sobre as especificidades da inovação em países periféricos voltada para mensuraçôes menos rigorosas da inovação, na direção do estudo da capacitação e potencial inovativo das empresas, especialmente nos processos adaptativos não tecnológicos, abordagens estas vinculadas ao Manual de Bogotá da RICYT.

A configuração final da Pintec 2000 procurou satisfazer essas diferentes demandas. Adotou-se um modelo adaptado da segunda edição do Manual de Oslo e do CIS-3, compreendendo uma seção robusta acerca das atividades e do pessoal ocupado em P\&D. Também foram adotadas uma operacionalização meticulosa e algumas questôes acerca da origem do capital das empresas, de modo a levar em conta as especificidades da inovação em países periféricos, que raramente se dá a partir de atividades formais de $P \& D$ e mais frequentemente por meio de processos adaptativos de tecnologias advindas de empresas multinacionais. É possível, portanto, dizer que a Pintec assumiu, desde a sua gênese, um modelo "híbrido", que procura contemplar informações mais completas acerca da P\&D empresarial dentro de um survey de inovação que está fundamentado no modelo elo de cadeia que embasa o Manual de Oslo. Observamos, porém, que este modelo "híbrido" tem limitaçôes, de 
modo que as escolhas conceituais-metodológicas na gênese da Pintec influenciaram, de fato, nos limites e alcances das estatísticas produzidas pela pesquisa.

O principal problema seria decorrente do fato de que a P\&D pode ser subestimada a partir das mensurações dos surveys de inovação. Isso porque, por um lado, enquanto os surveys de $\mathrm{P} \& \mathrm{D}$ executam praticamente censos das empresas que realizam atividades de $\mathrm{P} \& \mathrm{D}$, os surveys de inovação trabalham com amostras gerais de empresas e, por outro, dentro da lógica dos surveys de inovação, as empresas que não declararem ter inovado ou terem tido projetos de inovação incompletos ou abandonados no período de referência não respondem às questóes acerca das atividades inovativas. Ademais, também é digna de menção a problemática da subutilização dos indicadores provenientes dos surveys de inovação na formulação, monitoramento e avaliação de políticas públicas, algo que naturalmente não ocorre na mesma intensidade com os surveys de P\&D devido ao maior alinhamento das políticas públicas com as estatísticas de $\mathrm{P} \& \mathrm{D}$ e à racionalidade do modelo linear de inovação.

Apesar destas críticas e limitaçóes, a Pintec 2000 gerou relevantes impactos, tanto em termos de produção de conhecimento acerca da inovação no Brasil quanto em termos de possibilidades de sugestôes para políticas públicas e gestão empresarial no país. Além disso, por se tratar de um survey de inovação fundamentado no modelo elo de cadeia, os indicadores da Pintec 2000 permitem uma compreensão mais acurada do processo de inovação do que os indicadores de um survey de $\mathrm{P} \& \mathrm{D}$, ao mesmo tempo que, abordando a $\mathrm{P} \& \mathrm{D}$ de uma maneira menos rigorosa, a pesquisa consegue abranger atividades ocasionais e informais de $P \& D$, algo disseminado em países periféricos. Assim, embora seja uma pesquisa "híbrida" e tenha restrições por conta disso, a Pintec inegavelmente é bastante original em sua origem, permitindo uma interessante visão integrada entre um survey de $\mathrm{P} \& \mathrm{D}$ e um survey de inovação.

\section{Referências bibliográficas}

ARCHIBUGI, D.; SIRILLI, G. The direct measurement of technological innovation in business. In: EUROPEAN COMMISSION CONFERENCE ON INNOVATION AND ENTERPRISE CREATION: STATISTICS AND INDICATORS, Paris, 23-24 Nov. 2000. Proceedings... Luxembourg: European Commission, 2000.

ARUNDEL, A. Innovation survey indicators: what impact on innovation policy? In: OECD (Org.). Science, technology and innovation indicators in a changing world: responding to policy needs. Paris, 2007. 
BAPTISTA, B.; BERNHEIM, R.; GARCÉ, A.; HERNÁNDEZ, E. Consulta a tomadores de decisión en politicas públicas de ciencia, tecnología e innovación sobre sus fuentes de información. Informe regional. [S.1.]: Banco Interameticano de Desarrollo (BID), Sector Social - División de Ciencia y Tecnología, 2010.

BARRÉ, R. S\&T indicators for policy making in a changing science-society relationship. In: MOED, H.; GLÄNZEL, W.; SCHMOCH, U. (Ed.). Handbook of quantitative science and technology research. New York: Kluwer Academic Publishers, 2004.

BARRÉ, R.; PAPON, P. Économie et politique de la science et de la technologie. Paris: Editeur Hachette, 1993 (Collection Pluriel).

BASTOS, C.; REBOUÇAS, M.; BIVAR, W. A construção da Pesquisa Industrial de Inovação Tecnológica (Pintec). In: VIOTTI, E. B.; MACEDO, M. M. (Org.). Indicadores de ciência, tecnologia e inovação no Brasil. Campinas: Editora da Unicamp, 2003.

BERNARDES, R. Produção de estatísticas e inovação tecnológica: Paep 1996-2001. São Paulo em Perspectiva, São Paulo, v. 17, n. 3-4, p. 151-167, 2003.

BRASIL - Ministério da Ciência e Tecnologia. Programa de Apoio ao Desenvolvimento Cientifico e Tecnológico - PADCT-III: documento básico. Brasília, 1998.

. Ciência, tecnologia e inovação: desafio para a sociedade brasileira - Livro Verde. Brasília, 2001.

CAMARGO, A. Sociologia das estatísticas: possibilidades de um novo campo de investigação. História, Ciências, Saúde-Manguinhos, Rio de Janeiro, v. 16, n. 4, p. 903-925, 2009.

CAMPOS, N.; IOOTTY, M. Institutional barriers to firm entry and exit: case-study evidence from the Brazilian textiles and eletronics industries. Economic Systems, Regensburg, v. 31, p. 346-363, 2007.

DE NEGRI, J.; SALERNO, M. (Org.). Inovaçôes, padrôes tecnológicos e desempenho das firmas industriais brasileiras. Brasília: Ipea, 2005.

ERBER, F. Inovação tecnológica na indústria brasileira no passado recente: uma resenha da literatura econômica. Brasília: Cepal/Ipea, 2010 (Textos para discussão Cepal-Ipea, n. 17).

ESTERLE, L.; THEVES, J. Analysis of the different European systems for producing indicators. In: WORKSHOP ON S\&T INDICATORS PRODUCTION. Lisbon, 22-23 Sep. 2005.

EUROSTAT - Statistical Office of the European Union. The third Community Innovation Survey (CIS-3): harmonized questionnaire. Luxembourg, 2001. 
FRANCOZ, D.; PATINSON, B. Achieving reliable results from innovation surveys - methodological lessons learned from experience in OECD member countries. In: EUROPEAN COMMISSION CONFERENCE ON INNOVATION AND ENTERPRISE CREATION: STATISTICS AND INDICATORS. Paris, 23-24 Nov. 2000. Proceedings... Luxembourg: European Commission, 2000.

FREEMAN, C.; SOETE, L. Developing science, technology and innovation indicators: what we can learn from the past. Research Policy, Amsterdam, v. 38, p. 583-589, 2009.

GAULT, F. Social impacts of the development of science, technology and innovation indicators. Maastricht: United Nations University - UNU/MERIT, 2011 (Working Paper Series, 2011-008).

GODIN, B. The rise of innovation surveys: measuring a fuzzy concept. Project on the History and Sociology of STI Statistics, Montréal, 2002 (Working Paper, n. 16).

GODIN, B. the emergence of science and technology indicators: why did governments supplement statistics with indicators? Research Policy, Amsterdam, v. 32, n. 4, p. 679-691, 2003.

HANSEN, J. Technology innovation indicators: a survey of historical development and current practice. In: FELDMAN, M; LINK, A. (Ed.). Innovation policy in the knowledge-based economy. New York: Springer Science+Business Media, 2001.

IBGE - Instituto Brasileiro de Geografia e Estatística. Pesquisa Industrial Inovação Tecnológica 2000. Rio de Janeiro, 2002.

Pesquisa Industrial de Inovação Tecnológica. Rio de Janeiro, 2004 (Série Relatórios Metodológicos, v. 30).

KANNEBLEY, S.; PORTO, G.; PAZELLO, E. Characteristics of Brazilian innovative firms: an empirical analysis based on PINTEC - Industrial Research on Technological Innovation. Research Policy, Amsterdam, v. 34, p. 872-893, 2005.

KLINE, S.; ROSERNBERG, N. An overview of innovation. In: LANDAU, R.; ROSENBERG, N. (Ed.). The positive sum strategy. Washington: National Academy of Press, 1986. MATESCO, V. Esforço tecnológico das empresas brasileiras. Brasília: Ipea, 1994a (Texto para discussão, n. 333).

MATESCO, V. O comportamento estratégico das empresas industriais brasileiras: inovadoras versus não-inovadoras. Brasília: Ipea, 1994 b (Texto para discussão, n. 336). 
NELSON, R. National innovation systems: a comparative analysis. New York: Oxford University Press, 1993.

OECD - Organization for Economic Co-operation and Development. Proposed guidelines for collecting and interpreting technological innovation data - Oslo Manual. Paris, 1992.

PACHECO, C. Politicas públicas, intereses y articulación política: cómo se gestaron las recientes reformas al sistema de ciencia y tecnología en Brasil. Santiago de Chile: Cepal, 2005 (Serie Políticas Sociales, n. 103).

. As reformas da politica nacional de ciência, tecnologia e inovação no Brasil (19992002). Santiago de Chile: Cepal, 2007 (Manual de Políticas Públicas).

ROMEIRO, M.; PREARO, L.; SILVEIRA, M.; RIBEIRO NETO, J. Pesquisa sobre inovação tecnológica: o possível viés da informação em levantamentos. Revista Brasileira de Inovação, Campinas, v. 13, n. 1, p. 133-162, 2014.

SALAZAR, M.; HOLBROOK, A. A debate on innovation surveys. Science and Public Policy, Cranleigh, v. 31, n. 4, p. 254-266, 2004.

SELLTIZ, C.; JAHODA, M.; DEUTSCH, M.; COOK, S. Métodos de pesquisa nas relaçôes sociais. Tradução de Dante Moreira Leite. São Paulo: Editora Pedagógica e Universitária e Editora da Universidade de São Paulo, [1959] 1975.

SENRA, N. A sociologia das estatísticas como norte da pesquisa histórica das estatísticas. In: XXVIII INTERNATIONAL CONGRESS OF THE LATIN AMERICAN STUDIES ASSOCIATION. Anais... Rio de Janeiro, 2009.

SILVA, D. O processo de construção conceitual-metodológica da PINTEC. 2015, $144 \mathrm{f}$. Dissertação (Mestrado em Política Científica e Tecnológica) - Universidade Estadual de Campinas, Campinas, 2015.

SMITH, K. Measuring innovation. In: FAGERBERG, I.; MOWERY, D.; NELSON, R. (Ed.). The Oxford handbook of innovation. Oxford: Oxford University Press, 2004.

STOKES, D. O quadrante de Pasteur: a ciência básica e a inovação tecnológica. Campinas: Editora da Unicamp, [1997] 2005 (Clássicos da Inovação).

VELHO, L. Indicadores de C\&T e seu uso em política científica. Sociedade e Estado, Brasília, v. 7, n. 1, p. 63-77, 1992.

. Estratégias para um sistema de indicadores de C\&T no Brasil. Parcerias Estratégicas, Brasília, v. 13, p. 109-121, 2001.

VIOTTI, E. Fundamentos e evolução dos indicadores de CT\&I. In: VIOTTI, E. B.; MACEDO, M. M. (Org.). Indicadores de ciência, tecnologia e inovação no Brasil. Campinas: Editora da Unicamp, 2003. 